UNIVERSITE DE LAUSANNE - FACULTE DE BIOLOGIE ET DE MEDECINE

Département médico-chirurgical de pédiatrie

Service de pédiatrie

\title{
Shorter time to diagnosis and improved stage at presentation in Swiss patients with retinoblastoma treated from 1963 to 2004.
}

\section{THESE}

préparée sous la direction du Docteur Maja Beck-Popovic, Privat-Docent et Maître d'Enseignement et de Recherche,

et présentée à la Faculté de biologie et de médecine de l'Université de Lausanne pour l'obtention du grade de

\author{
DOCTEUR EN MEDECINE
}

par

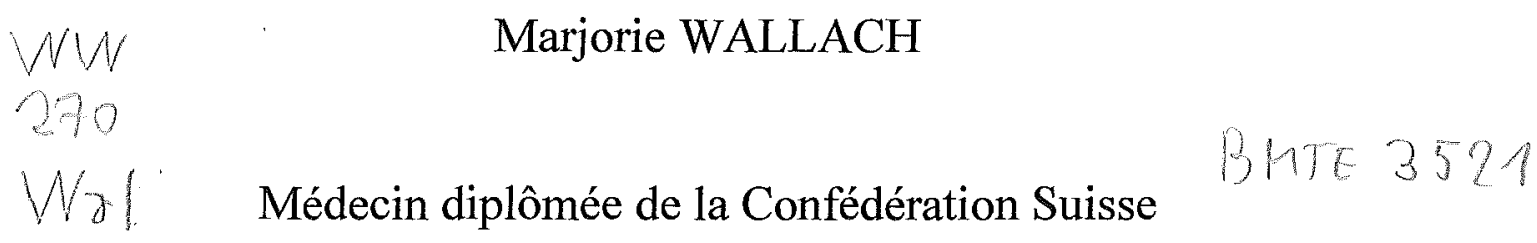

Originaire de Bagnes (VS)

Lausanne 


\section{Imprimatur}

Vu le rapport présenté par le jury d'examen, composé de

Directeur de thèse Madame le Docteur Maja Beck-Popovic

Co-Directeur de thèse

Expert Monsieur le Professeur associé Francis Munier

Directrice de l'Ecole Madame le Professeur Stephanie Clarke doctorale

la Commission MD de l'Ecole doctorale autorise l'impression de la thèse de

$$
\text { Madame Marjorie WALLACH }
$$

intitulée

Shorter time to diagnosis and improved stage at presentation in Swiss patients with retinoblastoma treated from 1963 to 2004

Lausanne, le 31 mars 2009

$$
\text { pour Le Doyen }
$$

de la Faculté de Biologie et de Médecine

Madame le Professeur Stephanie Clarke Directrice de l'Ecole doctorale 


\section{$\underline{\text { Rapport de synthèse }}$}

\section{Shorter time to diagnosis and improved stage at presentation in Swiss patients with retinoblastoma treated from 1963 to 2004.}

\section{But :}

Le rétinoblastome est la tumeur de l'œil la plus fréquente chez l'enfant. Un diagnostic précoce est important pour sauver le globe oculaire et la survie du patient. Le but de notre étude est de déterminer l'évolution de l'intervalle diagnostique, c'est-à-dire le délai entre les premiers symptômes et la date du diagnostic officiel du rétinoblastome, sur une période de 40 ans en Suisse.

\section{Matériel et méthode :}

Il s'agit d'une étude rétrospective faite sur 139 patients suisses traités pour rétinoblastome durant trois différentes périodes: (1) 1963-1983; (2) 1984-1993; et (3) 1994-2004. On compare certaines caractéristiques : le sexe du patient, la latéralité de la maladie, les premiers symptômes, leurs observateurs, l'intervalle diagnostique, l'âge au diagnostic, le stade de la maladie, l'histoire familiale.

\section{Résultats :}

37 patients $(26.6 \%)$ ont été traités dans la première période ; $44(31.7 \%)$ dans la période 2 et $58(41.7 \%)$ dans la période 3 . L'intervalle diagnostique diminue de façon significative de 6.97 mois dans la période 1 à 3.58 dans la période 2 à 2.25 dans la période 3 pour le total des malades. Ceci reste significatif pour les rétinoblastomes unilatéraux. De plus, dans ce même groupe, on observe une diminution significative des stades avancés de la maladie, groupe $\mathrm{E}$ selon Murphree (61.5\% dans la période $1 ; 46.7 \%$ dans la période 2 et $22.2 \%$ dans la période 3).

Lorsque la maladie est bilatérale, les mêmes observations se font de façon un peu moins marquée.

Il n'y a aucun patient diagnostiqué au stade $E$ de la maladie en présence d'une anamnèse familiale positive. Leucocorie $(48.2 \%)$ et strabisme $(20.1 \%)$ sont les symptômes les plus fréquents durant les 3 périodes. Les seuls facteurs qui influencent significativement le risque d'avoir un stade E de la maladie sont la durée de l'intervalle diagnostic et la période de diagnostic.

\section{Conclusion :}

On constate un progrès dans le diagnostic du rétinoblastome en Suisse, surtout lors de maladie unilatérale. De même, des améliorations sont notées dans la maladie bilatérale mais de façon non significative. Il est donc important de mieux enseigner aux médecins à reconnaître les symptômes oculaires de la maladie et à référer les patients plus tôt aux spécialistes. 


\title{
Shorter Time to Diagnosis and Inoroved Stage at Presentation in Swriss Pathens With Tetinoblastoma Treated From 1963 ro 2004
}

\author{
Marjorie Wallach, MDa, Aubin Balmer, MDb, Francis Munier, MD', Susan Houghton, DBOb, Sandro Pampallona, BScls, PhDc, \\ Nicolas von der Weid, MDa, Maja Beck-Popovic, MDa, on behalf of the Swiss Pediatric Oncology Group and the Swiss Childhood Cancer \\ Registry
}

aPediatric Hematology-Oncology Unit, Centre Hospitalier Universitaire Vaudois, Lausanne, Switzerland; 'Ophthalmology Department, Jules Gonin Eye Hospital, Lausanne, Switzerland; ForMed, Statistics for Medicine, Evolène, Switzerland

The authors have indicated they have no financial relationships relevant to this article to disclose.

\section{A}

OBJECTIVES. Retinoblastoma is the most frequent intraocular malignancy in children. Early diagnosis is essential for globe salvage and patient survival. The aim of our study was to determine how time to diagnosis of retinoblastoma has evolved over a 40-year period in Switzerland.

METHOD AND PATIENTS. A retrospective study of 139 Swiss patients with retinoblastoma was performed comparing 3 periods: (1) 1963-1983; (2) 1984-1993; and (3) 1994-2004. Factors taken into account were gender, laterality of retinoblastoma, age at first symptoms, type and first observer of symptoms, time to diagnosis, age at diagnosis, disease stage, and family history.

RESULTS. Thirty-seven patients $(26.6 \%)$ were treated in period $1,44(31.7 \%)$ in period 2, and $58(41.7 \%)$ in period 3. Overall, the diagnostic interval decreased in a significant way from 6.97 months in period 1 to 3.58 in period 2 and to 2.25 in period 3. When looking separately at unilateral and bilateral disease, the decrease of the diagnostic interval remained statistically significant in unilateral retinoblastoma; there was also a significant reduction in the number of patients with advanced group E disease (Murphree classification) $(61.5 \%$ in period $1,46.7 \%$ in period $2,22.2 \%$ in period 3 ). In bilateral disease, the same observations were made to a lesser extent. However, there were no cases with group $\mathrm{E}$ disease in 10 patients with positive family history. Leukocoria $(48.2 \%)$ and strabismus $(20.1 \%)$ were the 2 most frequent symptoms throughout the 3 periods. The only factors that statistically influenced the chances of having a diagnosis of group $\mathrm{E}$ disease were the diagnostic interval and period of diagnosis.

CONCLUSIONS. Progress has been made in the diagnosis of retinoblastoma in Switzerland, notably in unilateral disease. Improvement to a lesser extent has also been observed in bilateral cases but without statistical significance. Greater effort is www.pediatrics.org/cgi/doi/10.1542/ peds.2006-0781

doi:10.1542/peds.2006-0784

Key Words retinoblastoma, diagnostic interval, disease stage

Abbrevlations

Dl-diagnostic interval

$\mathrm{FH}^{+1}$ - - famlly history-positive/negative

Accepted for publication May 5, 2006

Address correspondence to Maja BeckPopovic, MD, Pediatric Hematology-Oncology Unit, Universily Haspital CHUV, 1011 Lausanne, Swizeiland. E-mail: mająabeckpopovic@chuv.ch

PEDIATRICS (ISSN Numbers: Print, 0031-4005; Online, 1098-4275). Copyright $\theta 2006$ by the American Academy of Pediatrics 
needed to teach physicians-in-training to recognize the importance of ocular symptoms and refer patients earlier.

$\mathrm{R}$ ETINOBLASTOMA IS THE most common intraocular malignancy in children. It results from malignant transformation of primitive retinal cells, has an incidence of $\sim 1$ in 14000 to 1 in $34000,,^{1-3}$ and may be unilateral or bilateral. All bilateral cases and $15 \%$ of the unilateral cases are hereditary, but only $3 \%$ to $15 \%$ of patients have a positive family history. The disease is so rare that a primary care physician is unlikely to see more than 1 case of retinoblastoma in his or her career. It is crucial, therefore, to educate practitioners in the recognition of the major presenting signs such as leukocoria and strabismus, as well as the rarer inflammatory symptoms. ${ }^{4}$ The individual signs will depend on tumor size and location and are frequently intermittent. This makes diagnosis more difficult and dependent on the pediatrician's or general practitioner's ability to recognize the significance of these signs and refer the child to a specialist, and dependent on the regional screening program.

Retinoblastoma is diagnosed at an average age of 18 months (more specifically, 9 months for bilateral cases and 24 months for unilateral disease). ${ }^{5}$ Late diagnosis or late referral increases the risk of advanced disease and lessens the chances of cure. ${ }^{6,7}$ Although retinoblastoma is diagnosed later in developing countries, ${ }^{6,8,9}$ a positive family history clearly reduces the time to diagnosis. ${ }^{10.11}$

In countries with well-developed medical care, information on the interval between the onset of first symptoms and the time to diagnosis of retinoblastoma is relatively scarce. In Switzerland, access to medical care is facilitated, and, since 1960, most patients with retinoblastoma have been treated at the national reference center, which specializes in the treatment of ocular tumors in children and adults. The goal of this study was to determine how time to diagnosis of retinoblastoma has evolved over a 40-year period in Switzerland.

\section{PATIENTS AND METHODS}

We conducted a retrospective study on all Swiss resident patients who were given a diagnosis of retinoblastoma between 1963 and 2004, most of whom were treated at the national reference center. Of the 452 patients who came from different countries and were treated during this period at the Lausanne retinoblastoma clinic, 139 Swiss patients were included into the study. For those patients treated at other Swiss centers, data were completed with the help of the national childhood cancer registry and local pediatric oncologists. Information was retrieved from the local database and patients' files and included gender, laterality of retinoblastoma, age at first symptoms, type of symptoms, the first person to observe the symptoms, the interval between first symptoms and diagnosis (diagnostic interval [DI]), age at diagnosis, dis. ease stage, family history of retinoblastoma, and the reason for the consultation.

Tumor stage was determined by the ophthalmologist at the initial investigation under general anesthesia. The patients' disease stage was evaluated according to the Reese-Ellsworth classification system, which is based on the possibility of globe preservation by radiotherapy..$^{12}$ Since the introduction of chemotherapy as the preferential treatment modality for retinoblastoma 10 years ago, a new classification system has been developed that considers the probability of globe preservation by chemotherapy (Murphree classification ${ }^{13}$ ). A classification for both classification systems was recorded for all patients, on a retrospective basis for the earlier cases. The latter as well as patients included in the study from other centers were reclassified by the Lausanne ophthalmologists on the basis of lundoscopy findings and/or histology. The Murphree classification was chosen for this study, and the observation time was divided into 3 periods: (1) 1963-1983; (2) 1984-1993; and (3) 19942004. Patients with retinoma were excluded.

The $t$ test or 1-way analysis of variance was used to compare $\geq 2$ or more means, respectively. The $\chi^{2}$ test for independence was used to compare proportions. A logistic regression on 113 cases with complete observations was performed to study the simultaneous effect of age, gender, laterality, presence of strabismus, presence of leukocoria, period of diagnosis, and diagnostic delay on the risk of presenting with a Murphree group $\mathrm{E}$ classification. To allow for a possible difference in the role of delay between unilateral and bilateral cases, an interaction term was also considered between delay and laterality. A term for positive familial history could not be fitted because no patient in that category had a group E classification. All factors, grouped as shown in Table 1, were coded in terms of corresponding binary variables. A forward-selection procedure was applied to identify the minimum set of variables predicting the stage. The results are presented in terms of relative risk (as approximated by the odds ratio) of group $\mathrm{E}$ classification at diagnosis, the corresponding $95 \%$ confidence interval, and $P$ value (Wald's test). All $P$ values are from 2 -sided tests. Analyses were performed with SPSS 13 software (SPSS Inc, Chicago, LL).

\section{RESULTS}

\section{General Data}

Between 1963 and 2004, 452 patients were given a diagnosis of and treated for retinoblastoma at the Jules Gonin Eye Hospital in Lausanne, 139 of whom were Swiss patients. This represents 3 to 4 new cases per year in Switzerland and an incidence of 1 in 24000 live births. ${ }^{14}$ Table 1 shows the patients' characteristics. 
TABLE 1 Patient Characteristics

\begin{tabular}{|c|c|}
\hline & $n(\%)$ \\
\hline \multicolumn{2}{|l|}{ Gender } \\
\hline Male & $75(54.0)$ \\
\hline Female & $63(45.3)$ \\
\hline Missing & $1(0.7)$ \\
\hline \multicolumn{2}{|l|}{ Laterality } \\
\hline Unitateral & $93(66.9)$ \\
\hline Bilateral & $46(33.1)$ \\
\hline \multicolumn{2}{|l|}{ Reason for consultation } \\
\hline Leukocoria & $67(48.2)$ \\
\hline Strabismus & $28(20.1)$ \\
\hline Others signs & $16(11.5)$ \\
\hline Positive family history & $11(7.9)$ \\
\hline Strabismus and leukocoria & $9(6.5)$ \\
\hline No symptoms & $2(1.4)$ \\
\hline No information & $6(4.3)$ \\
\hline \multicolumn{2}{|l|}{ First signs' observer } \\
\hline Parents & $108(77.7)$ \\
\hline Friends/relatives & $4(2.9)$ \\
\hline Pediatrician & $3(2.2)$ \\
\hline Ophthalmologist & $2(1.4)$ \\
\hline Positive familial history & $9(6.5)$ \\
\hline Others & $4(2.9)$ \\
\hline Missing & $9(6.5)$ \\
\hline \multicolumn{2}{|l|}{ Age at diagnosis, mo } \\
\hline$<6$ & $32(23.0)$ \\
\hline $6.1-12$ & $36(25.9)$ \\
\hline $12.1-24$ & $22(15.8)$ \\
\hline$>21$ & $49(35.3)$ \\
\hline \multicolumn{2}{|l|}{ Murphree classification } \\
\hline$A$ & $3(2.2)$ \\
\hline B & $12(8.6)$ \\
\hline$C$ & $6(4.3)$ \\
\hline $\mathrm{D}$ & $52(37.1)$ \\
\hline$E$ & $47(33.8)$ \\
\hline Missing & $19(13.7)$ \\
\hline \multicolumn{2}{|l|}{ Mean diagnostic interval, mo } \\
\hline$<1$ & $52(37.4)$ \\
\hline $1.1-3$ & $35(25.2)$ \\
\hline $3.1-6$ & $27(19.4)$ \\
\hline$>6$ & $17(12.2)$ \\
\hline Missing & $8(5.8)$ \\
\hline \multicolumn{2}{|l|}{ Years of diagnosis } \\
\hline $1963-1983$ & $37(26.6)$ \\
\hline $1984-1993$ & $44(31.7)$ \\
\hline $1994-2004$ & $58(41.7)$ \\
\hline
\end{tabular}

There was a slight male predominance, with $54 \%$ boys to $46 \%$ girls. Two thirds had unilateral $(66.9 \%)$ and one third had bilateral $(33.1 \%)$ disease. The most common presenting signs were leukocoria $(48.2 \%)$, followed by strabismus $(20.1 \%)$. Only a few patients consulted for positive family history $(7.9 \%)$. Parents were the first to observe disease symptoms in $77.7 \%$ of the cases. The age at diagnosis was $<6$ months in $23 \%, 6.1$ to 12 months in $25.9 \%, 12$ to 24 months in $15.8 \%$, and $>24$ months in $35.3 \%$ of the patients. Disease group distribution was as follows: group A, 3 of 139 (2.2\%); group B, 12 of 139 (8.6.\%); group C, 6 of $139(4.3 \%)$; group D, 52 of 139 $(37.4 \%)$; group E, 47 of $139(33.8 \%)$. Group A represents very localized and less advanced disease, and group $\mathrm{E}$ represents the most advanced disease stage. Patients were distributed within the 3 periods as follows: (1) $1963-1983,37$ patients $(26.6 \%)$; (2) 1984-1993, 44 patients $(31.7 \%)$; (3) 1994-2004, 58 patients $(41.7 \%)$.

\section{Dl, Age at Diagnosis, and Stage of Disease}

Table 2 shows the DI, age at diagnosis, and Murphree group $\mathrm{E}$ according to the period. Overall, the mean DI decreased from 6.9 months in the first period to 3.5 months in the second and 2.2 months in the third $(P=$ $.011)$. This decrease was more significant in unilateral disease, with 8.5 months in the first period, 4 months in the second period, and 1.7 months in the third period $(P$ $=.012$ ). In bilateral disease the DI remained more constant over time, with 4.2 months in the first period, 1.8 months in the second period, and 3.1 months in the third period.

The mean age at diagnosis was 21.8 months overall, with 21.1 months for the first period, 25.3 months for the second period, and 19.6 months for the third period. Patients with bilateral disease received their diagnosis earlier at an overall mean of 11.1 months of age, with 12.8 months in period $1,8.8$ months in period 2 , and 11.0 months in period 3. Patients with unilateral disease were given their diagnosis at an overall mean age of 27.1 months, corresponding to 26.8 months in period $1,30.2$ months in period 2 , and 24.5 months in period 3 .

The occurrence of advanced group $E$ disease decreased over time, from a mean of $60 \%$ of patients in period 1 to $46.2 \%$ in period 2 and $25 \%$ in period $3(P=$ $.007)$. This was notably the case in unilateral retinoblastoma; group E classification was recorded as $61.5 \%$ in period $1,46.7 \%$ in period 2 , and $22.2 \%$ in period $3(P=$

TABLE 2 DI, Age at Diagnosis, and Disease Group According to Periods

\begin{tabular}{|c|c|c|c|c|c|c|c|c|c|c|c|c|c|c|c|}
\hline & \multicolumn{4}{|c|}{ Unilateral } & \multirow[t]{2}{*}{$P$} & \multicolumn{4}{|c|}{ Bilateral } & \multirow[t]{2}{*}{$P$} & \multicolumn{4}{|c|}{ Total } & \multirow[t]{2}{*}{$P$} \\
\hline & $\begin{array}{c}\text { Up } \\
\text { to } \\
1983\end{array}$ & $1984-1993$ & $\begin{array}{c}1994 \\
\text { and } \\
\text { After }\end{array}$ & Total & & $\begin{array}{c}\text { Up } \\
\text { to } \\
1983\end{array}$ & 1984-1993 & $\begin{array}{c}1994 \\
\text { and } \\
\text { After }\end{array}$ & Total & & $\begin{array}{c}\text { Up } \\
\text { to } \\
1983 \\
\end{array}$ & $1984-1993$ & $\begin{array}{c}1994 \\
\text { and } \\
\text { After }\end{array}$ & Total & \\
\hline $\mathrm{Dl}, \mathrm{mo}$ & 8.54 & 4.03 & 1.74 & 4.04 & $.012^{\mathrm{a}}$ & 4.25 & 1.86 & 3.15 & 3.16 & .335 & 6.97 & 3.58 & 2.25 & 3.76 & $.011^{\circ}$ \\
\hline Age, mo & 26.89 & 30.22 & 24.53 & 27.17 & .658 & 12.82 & 8.88 & 11.05 & 11.16 & .601 & 21.19 & 25.37 & 19.65 & 21.87 & .459 \\
\hline Murphree $E, \%$ & 61.5 & 46.70 & 22.20 & 38.0 & $.02^{\mathrm{a}}$ & 58.3 & 44.4 & 30.0 & 41.5 & .283 & 60.0 & 46.2 & 25.0 & 39.2 & .007 \\
\hline
\end{tabular}

a Statistically significant results. 
.02). In bilateral disease, the tendency was clearly the same but did not reach statistical significance.

The influence of gender, age at diagnosis, laterality, stage, period of diagnosis, observers, and type of symptoms as risk factors for delay in diagnosis was analyzed by a logistic-regression analysis. The only factors that statistically influenced the chances of being given a diagnosis of group $\mathrm{E}$ disease were the DI and period of diagnosis, which is illustrated in Table 3.

\section{Positive Family History}

The difference in DI with regard to disease group was most obvious among patients with positive family history $\left(\mathrm{FH}^{+}\right)$compared with those with negative family history $\left(\mathrm{FH}^{-}\right)$. Mean age at diagnosis was only 3.6 months in $\mathrm{FH}^{+}$families (mean DI: 0 months), whereas in $\mathrm{FH}^{-}$children, mean age at diagnosis was 23.5 months (mean DI: 4.09 months) $(P<.001)$. In $\mathrm{FH}^{+}$patients, no group E disease was recorded (0 of 10), compared with $42.5 \%$ (45 of 106$)$ in $\mathrm{FH}^{-}$patients. The data are summarized in Table 4.

\section{DISCUSSION}

It is well known that smaller tumors and less-advanced disease stage offer better chances for cure. This is also true for retinoblastoma, especially with the progress in treatment over the past 20 years. Currently, $>90 \%$ of children with retinoblastoma survive their disease. ${ }^{1,15}$ In recent years, more-conservative eye-sparing treatment has enabled children to be cured with less morbidity, in particular, by avoiding external beam radiation and using chemotherapy. ${ }^{16}$ This strategy, however, is mostly successful in less-advanced retinoblastoma, Murphree stage A through $\mathrm{C}$ or Reese-Ellsworth stage I through III, as shown in earlier studies. ${ }^{17,18}$ Advanced stages of disease continue to require enucleation and/or external beam radiotherapy, the latter with increased risks for visual impairment, severe cosmetic deformities, and secondary malignancies. ${ }^{19.20}$ Experience from developing countries clearly shows that advanced age and delayed diagnosis increase the risk of extraocular disease and diminish the perspective for cure..$^{21,22}$

In Switzerland, access to medical care is facilitated by short traveling distances and the obligatory health insur-

TABLE 3 Risk for Group E Disease in Relationship to Period and DI

\begin{tabular}{lcc}
\hline & Risk of Stage $E$ & 95\% Confidence Interval $(P)$ \\
\hline Period & & \\
3: $1994-2004$ & 1.00 & $0.99-6.35(.053)$ \\
$2: 1984-1993$ & 2.50 & $1.15-11.39(.028)$ \\
$1: 1963-1983$ & 3.62 & \\
DI & & \\
$<1$ mo & 1.00 & $0.5-4.00(.518)$ \\
$1-3$ mo & 1.41 & $0.59-5.25(.306)$ \\
$3-6$ mo & 1.77 & $1.86-35.23(.005)$ \\
$>6$ mo & 8.09 & \\
\hline
\end{tabular}

TABLE 4 Characteristics of Patients With and Without Positive Family History

\begin{tabular}{lcc}
\hline & $\mathrm{FH}^{+}$ & $\mathrm{FH}^{-}$ \\
\hline Age at diagnosis, mo $(P<.001)$ & 3.6 & 23.5 \\
DI, mo $(P<.001)$ & 0.00 & 4.09 \\
Disease's stage, Murphree $A-D, \%(n)$ & $100.0(10)$ & $57.5(61)$ \\
Murphree stage $\mathrm{E}_{1} \%(n)(P=, 006)$ & $0.0(0)$ & $42.5(4.5)$ \\
\hline
\end{tabular}

ance system. Access to specialized centers has also improved during recent years. We were interested, therefore, in determining how diagnosis of a rare disease such as retinoblastoma has evolved over a 40 -year period.

Our results are consistent with those of other studies concerning gender distribution and the proportion of patients with unilateral $(60 \%)$ and bilateral $(40 \%)$ disease. ${ }^{5.23}$

Similar to previous large studies, we identified leukocoria as the most common initial symptom, followed by strabismus. ${ }^{24,25}$ The symptoms did not change over time. In nearly $80 \%(77.7 \%)$ of the cases the parents were the first to observe an ocular abnormality in their child. ${ }^{26}$ This serves as a reminder that parents should be listened to carefully when describing the symptoms they observed in their children. On the other hand, it is worrisome that only $2.2 \%$ of pediatricians detected ocular signs first, because checking for a red fundus reflex is part of a young child's periodic pediatric examination. Age at diagnosis was higher in unilateral (27.1 months) than bilateral (11.16 months) retinoblastoma, similar to that reported in the literature. Indeed, Goddard et $\mathrm{al}^{5}$ found a mean age at diagnosis of 9 months for bilateral and 24 months for unilateral disease, and Butros et al ${ }^{26}$ found a mean age of 12.8 months in bilateral and 23.3 months in unilateral retinoblastoma. As a whole, half of our patients were given their diagnosis before the age of 1 year. It is interesting to note that Wirix et $\mathrm{al}^{27}$ showed a difference of age at diagnosis related to the type of symptoms. Patients with leukocoria were younger (mean age: 20.6 months) at diagnosis than patients with strabismus (mean: 32 months). This is not surprising, because strabismus would normally develop only when central vision is impaired by a macular tumor that is most often unique, in contrast to any peripheral, often multifocal tumor location that can cause leukocoria, which is easier to detect by the family. In our study, no relationship was found between the type of symptoms and age at diagnosis or laterality.

As shown in Table 2, the main finding in our patients was the reduction in the DI over time $(P=.011)$. When the series was stratified according to laterality, this reduction remained statistically significant in patients with unilateral retinoblastoma but showed only a trend in bilateral disease, although the latter started with a shorter DI already in the first period. Age at diagnosis, however, remained unchanged, as did the symptoms. It 
might have been expected that a better recognition of symptoms would reduce the DI in both bilateral and unilateral cases, with leukocoria being the main symptom in both patient groups. A concomitant increase of strabismus as the main symptom in bilateral retinoblastoma could be a plausible explanation, because "malignant" strabismus is always more difficult to recognize and differentiate from "banal" strabismus, whereas leukocoria, once detected, is always alarming. The retrospective nature of our study limits the conclusions that can be drawn, with insufficient information on the specific time to reaction or DIs by the parents, pediatrician, general practitioner, or ophthalmologist. We hypothesize that leukocoria in older children with unilateral retinoblastoma is recognized more rapidly and incites parents to consult the doctor, whereas younger children with bilateral retinoblastoma might experience a period of strabismus that goes unnoticed until the development of leukocoria alerts the parents to seek medical attention. Franzco et $\mathrm{al}^{23}$ found earlier diagnosis over time in bilateral retinoblastoma in a review of 165 patients over a 50-year period (divided into 3 parts). They explained this by a higher proportion of positive family history in bilateral retinoblastoma in the more recent time period, increasing the proportion of systematically screened children. They could not confirm this hypothesis statistically.

The majority of our patients $(82 \%)$ were given their diagnosis within 6 months from the first symptoms. This is shorter than the mean overall lag time of 8.3 months reported by Erwenne and Franco, ${ }^{21}$ who found that $47.7 \%$ of their patients had a DI of $>6$ months. The time limit of 6 months is an important factor, because diagnosis of bilateral retinoblastoma beyond 4 months seems to correlate with greater risk of blindness ${ }^{28}$ and compromises salvage treatment. ${ }^{26}$

The other important observation in our study is the progressively smaller number of patients who present with group $\mathrm{E}$ disease, notably in unilateral and with a clear tendency in bilateral disease (Table 2). Group E, the most advanced disease stage, is rarely curable by conservative treatment, with most cases requiring enucleation or radiotherapy. To discard the possibility of retrospective Murphree staging influencing the larger number of group E classifications in the early period, we checked group D disease, which showed complete stability throughout the observation periods, which supports a real decrease in group $\mathrm{E}$ disease. Another factor is the absence of group E disease in a small number of patients who were screened and given a diagnosis early on the basis of positive family history (Table 4). All these patients have been treated by local treatment alone or in combination with chemoreduction. Other authors also showed that early detection allows local intraocular treatment of small tumors with a much better chance of globe preservation and visual function. In a review of
250 patients, Haik et $\mathrm{al}^{29}$ demonstrated that in patients with positive family history, the time of first symptoms to diagnosis was 2 weeks to 5 months (mean age at diagnosis: 6 months), in contrast to patients with negative family history, who showed a time of first symptoms to diagnosis of 2 weeks to 57 months (mean age at diagnosis: 19 months). Abramson et $\mathrm{al}^{24}$ demonstrated a mean age at diagnosis of 10.8 months if there was positive family history and 7.7 months if both positive family history and screening were combined. Moll et al ${ }^{11}$ also established that screening reduces the age at diagnosis and recommended that it be repeated up to the age of 4 years, because some families remain unaware of the risk of recurrence of retinoblastoma despite all explanations given. This corresponds to our own procedure of combining genetic counseling with intrauterine ultrasound monitoring of pregnancies at risk for retinoblastoma and screening from birth until 10 years of age (Table 5).

\section{CONCLUSIONS}

We conclude that progress has been made in the diagnosis of retinoblastoma in Switzerland, notably in unilateral disease, with a reduction in both the DI and number of cases presenting with advanced-stage disease. The figures for bilateral cases have remained more constant, which leaves room for improvement in a disease that may be extensive in young children, compromising not only visual function but also globe salvage and even survival. It is our hypothesis that with the earlier age of onset in bilateral cases, strabismus in very young infants is common and an underlying disease less likely to be suspected than in the presence of leukocoria. It must be stressed to physicians-in-training that looking for a red fundus reflex must be part of every pediatric examination in young children and that strabismus denotes an obligation to refer the child to a general ophthalmologist for a first evaluation, after which the specialized team will be consulted as necessary. Swiss pediatric guidelines currently recommend the referral of patients to the ophthalmologist for any strabismus present at $\geq 4$ months or

\begin{tabular}{|c|c|c|}
\hline TABLE 5 & \multicolumn{2}{|c|}{$\begin{array}{l}\text { Recommendation for Screening of Patients With Positive } \\
\text { Family History }\end{array}$} \\
\hline \multicolumn{2}{|c|}{ Risk of Genetic Transmission } & 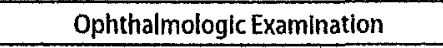 \\
\hline \multicolumn{2}{|c|}{$\begin{array}{l}50 \%-100 \% \text { Offspring from parents } \\
\text { with bilat eral hereditary } \\
\text { retinoblastoma }\end{array}$} & $\begin{array}{l}\text { Birth and at } 1,2,3,4,6,8,10,12,15,18,21 \text {, } \\
24,28,32,36,42 \text {, and } 48 \text { mo, under } \\
\text { general anesthesia; after } 48 \text { mo, annual } \\
\text { control until } 10 \text { y of age without } \\
\text { anesthesia }\end{array}$ \\
\hline \multicolumn{2}{|c|}{$\begin{array}{l}\text { 10\% Siblings of patients with } \\
\text { sporadic bilateral } \\
\text { retinoblastoma }\end{array}$} & $\begin{array}{l}\text { Birth and } 1,3,6,10,15,21,28,36 \text {, and } 42 \\
\text { mo, under general anesthesia; after } 48 \\
\text { mo, annual control until } 10 \text { y of age } \\
\text { without anesthesia }\end{array}$ \\
\hline \multicolumn{2}{|c|}{$\begin{array}{l}1 \% \text { Siblings of patients with } \\
\text { sporadic unilateral } \\
\text { retinoblastoma }\end{array}$} & $\begin{array}{l}\text { Birth and every } 6 \text { mo until } 48 \text { mo without } \\
\text { anesthesia }\end{array}$ \\
\hline
\end{tabular}


at a younger age in the case of persistent strabismus. Given the risk of rapid disease progression in infants, it is our opinion that referral of the patient after 1 month of age in cases of doubtful or persistent strabismus would be more appropriate.

\section{ACKNOWLEDGMENTS}

We thank the Swiss Childhood Cancer Registry and Gisela Michel for extracting the data from the registry. We also acknowledge the members of the Swiss Pediatric Oncology Group (SPOG) for their contribution to the study and the care of patients at their institutions: U. Caflisch (Lucerne); J. Greiner (St-Gallen); A. Hirt (Berne); T. Kühne (Basel); F. Niggli (Zürich); L. Nobile (Locarno); H. Ozsahin (Geneva); and R. Angst (Aarau).

\section{REFERENCES}

1. Moll AC, Kuik DJ, Bouter LM, et al. Incidence and survival of retinoblastoma in the Netherlands: a register based study 1862-1995. Br J Ophthalmol. 1997;81:559-562

2. Tamboli A, Podgor MJ, Horm JW. The incidence of retinoblastoma in the United States: 1974 through 1985. Arch Ophthalmol. 1990; 108:128-132

3. Sanders BM, Draper G., Kingston JE. Retinoblastoma in Great Britain 1969-1980: incidence, treatment, and survival. $\mathrm{Br} J$ Ophthalmol. 1988;72:576-583

4. Abramson DH, Frank CM. Susman M, et al. Presenting signs of retinoblastoma. $J$ Pediatr. 1998;132:505-508

5. Goddard A, Kingston JE, Hungerford JL. Delay in diagnosis of retinoblastoma: risk factors and treatment outcome. $\mathrm{Br} J \mathrm{Oph}$ thalmol. 1999:83:1320-1323

6. Schvartzman E, Chantada G, Fandino A, de Davila MT, Raslawski E, Manzitti J. Results of a stage-based approach for the treatment of retinoblastoma. $J$ Clin Oncol. 1996:14: $1532-1536$

7. Abramson DH, Ellsworth RM, Grumbach N, Sturgis-Buckhout L, Haik BG. Retinoblastoma: correlation between age at diagnosis and survival. I Pediatr Ophthalmol Strabismus. 1986;23: $174-177$

8. Kao LY, Su WW, Lin YW. Retinoblastoma in Taiwan: survival and clinical characteristics 1978-2000. Jpn J Ophthalmol. 2002; 46:577-580

9. Leal-Leal C, Flores-Rojo M, Cerecedo-Diaz F, et al. A multicentre report from the Mexican retinoblastoma group. $\mathrm{Br} J \mathrm{Oph}$ thalmol. 2004:88:1074-1077

10. Desjardins L. Ophthalmological tumors in children: diagnosis and therapeutic strategy [in French]. J Fr Ophtalmol. 2000;23: 926-939

11. Moll AC, Imhof SM, Meeteren AY, Boers M. At what age could screening for familial retinoblastoma be stopped? A register based study 1945-98. Br J Ophthalmol. 2000;84:1170-1172

12. Reese $A B$, Ellsworth $R$. The evaluation and current concept of retinoblastoma therapy. Trans Am Acad Ophthalmol Otolaryngol. $1963 ; 67: 164-172$

13. Murphree LA. Intraocular retinoblastoma: the case for a new group classification. Ophthalmol Clin North Am. 2005;18:41-53

14. Böhringer HR. Statistics, clinical characteristics and genetics of Swiss retinoblastoma patients (1926-1954) [in German]. Arch Julius Klaus Stift. 1956:31:1-16

15. Stiller CA. Population base survival rates for childhood cancer in Britain, 1980-1991. BMJ. 1994;309:1612-1616

16. Shields $\mathrm{CL}$, Shields JA. Recent developments in the management of retinoblastoma. J Pediatr Ophthalmol Sirabismus. 1999 36:8-18; quiz 35-36

17. Nenadov Beck M, Balmer A, Dessing C, Munier F. First-line chemotherapy can prevent external beam irradiation and enucleation in low-stage retinoblastoma. J Clin Oncol. 2000;18: 2881-2887

18. Murphree AL, Villablanca JG, Deegan WF 3rd, et al. Chemotherapy plus local treatment in the management of intraocular retinoblastoma. Arch Ophthalmol. 1996;114:1348-1356

19. Chan HS, Gallie BL, Munier FL, Beck Popovic M. Chemotherapy for retinoblastoma. Ophthalmol Clin North Am. 2005:18: $55-63$

20. Eng C, Li FP, Abramson DH, et al. Mortality from second tumors among long-term survivors of retinoblastoma. I Nat Cancer Inst. 1993;85:1121-1128

21. Erwenne CM, Franco EL. Age and lateness of referral as determinant of extraocular retinoblastoma. Ophthalmic Paediat Genet. 1989;10:179-184

22. Chantada G, Fandino A, Manzitti J, Urrutia L, Schvartzman E. Late diagnosis or retinoblastoma in a developing country. Arch Dis Child. 1999;80:171-174

23. Dondey JC, Staffieri S, McKenzie J, Davie G, Elder J. Retinoblastoma in Victoria, 1976-2000: changing management trends and outcomes. Clin Experiment Ophthalmol. 2004;32: $354-359$

24. Abramson $\mathrm{DH}$, Beaverson $\mathrm{K}$, Sangani $\mathrm{P}$, et al. Screening for retinoblastoma: presenting signs as prognosticators of patients and ocular survival. Pediatrics. 2003;112:1248-1255

25. Shields CL, Gorry T, Shields JA. Outcome of eyes with unilateral sporadic retinoblastoma based on the initial external findings by the family and the pediatrician. I Pediatr Ophthalmol Strabismus. 2004;41:143-149

26. Butros LJ, Abramson DH, Dunkel IJ. Delayed diagnosis of retinoblastoma: analysis of degree, cause, and potential consequences. Pediatrics. 2002;109(3). Available at: www.pediatrics. org/cgi/content/full/109/3/e45

27. Wirix M, Parys-Vanginderdeuren R, Casteels I, Uyttebrouck A Delayed diagnosis of retinoblastoma. Bull Soc Belge Ophtalmol. 2000; $(278): 37-41$

28. DerKinderen DJ, Koten JW, Van Romunde LKJ, et al, Early diagnosis of bilateral retinoblastoma reduces death and blindness. Int $J$ Cancer. 1989;44:35-39

29. Haik BG, Siedlecki A, Ellsworth RM, Sturgis-Buckhout L. Documented delays in the diagnosis of retinoblastoma. Anth Ophthalmol. 1985;17:731-732 